\title{
LA INTERPRETACIÓN DE LOS TRATADOS Y LA RAZÓN PRÁCTICA
}

\section{Ideas orientadoras y problemas principales de la interpretación de tratados}

"No hay parte del derecho de los tratados a la que el autor de un texto se acerque con más temor que la de la interpretación." He aquí las palabras iniciales del capítulo que Lord McNair ha dedicado a la interpretación de los tratados en su fundamental obra reciente sobre el derecho de los tratados. ${ }^{1}$ Semejante expresión de inseguridad puede causar asombro, porque emana de un erudito que, como autor distinguido y especialista práctico del derecho internacional, ha dirigido su mente a este problema por más de veinte años $^{2}$ y porque aparece después de que L'Institut de Droit International había consagrado tres sesiones de investigación intensiva al problema y convenido finalmente, sin una sola disensión, en los principios básicos que gobiernan la interpretación de los tratados. ${ }^{3}$

Sin embargo, las palabras de Lord McNair son muy convenientes si se considera que, al insistir en que "la tarea principal de cualquier tribunal solicitado para aplicar o explicar o interpretar un tratado" es "el deber de dar cumplimiento a la intención expresada por las partes", aún se atreve a adherirse a un punto de vista que fue abandonado por el Institut en sus Resoluciones. ${ }^{4}$ Asi, los principios de la interpretación de tratados continúan siendo un tema muy discutible, surcado de problemas insolutos y que conduce a aporias - a campos donde no hay "caminos" para la penetración cognoscitiva.

El hecho de que los tribunales internacionales se hayan ocupado constantemente de los problemas de la interpretación de tratados ${ }^{5}$ y hayan hecho

1 Véase Lord McNair, The Law of Treaties, 1961, 364. La discusión de la interpretación de los tratados suscita la cuestión: ¿qué constituye precisamente un tratado? En el Harvard Research in Inernational Law, Treaties, 1935, 29 (Suplemento), American Journal of International Law, 691, se adopta la opinión de que un tratado es "el instrumento, más bien que el acuerdo intangible, que registra a éste..., porque es el instrumento que puede ser visto y leido y que ha de ser interpretado y aplicado". Para una discusión de esta materia véase J. Basdevant, "La Conclusion et Redaction des Traités ct des Instruments Diplomatiques autres que les Traités", Recucil des Cours 15, 1926, 539. Para los fines presentes un tratado es cualquier instrumento que registra un acuerdo internacional.

2 Véase A. D. McNair, Law of Treaties: British Practice and Opinions, 1938.

3 Véase L'Institut de Droit International, Annuaire 46, 1956, 349 .

4 Véase Lord McNair, op. cit. supra en la n. 1, pág. $3^{6} 5$.

- Vease Sir Hersch Lauterpacht, The Development of International Law by The International Court, 1958, 26, quien dice que "la mayoría de los casos que han llegado ante el 
declaraciones elocuentes sobre puntos importantes de esta materia, no ha aportado mucho alivio intelectual en este campo. De la misma manera, el tratamiento del problema por generaciones de distinguidos juristas internacionales no ha aportado la claridad deseada; inclusive puede haber contribuido a la confusión predominante. ${ }^{6}$ El resultado que esas actividades produjeron es que tenemos actualmente sólo un arsenal más rico y elaborado de reglas de interpretación, que las partes en disputa, desplegando un poco de habilidad, pueden emplear para defender afirmaciones diametralmente opuestas. $^{7}$

Este estado de cosas, bastante desalentador, puede desanimarnos para abrirnos paso en las aporías de la interpretación de tratados, pero no nos justifica para desechar la búsqueda de los principios y métodos correctos que esta interpretación, como la de aquellos problemas de naturaleza abstracta, eternamente discutibles, de que sólo los teóricos tienen que ocuparse. EI problema es de suma importancia práctica, ya que la adecuada interpretación de una expresión utilizada en un tratado es a menudo el punto principal en los litigios internacionales, y aun con mayor frecuencia un auxiliar importante. Toda incertidumbre en cuanto a los principios apropiados de la interpretación afecta la seguridad de las relaciones jurídicas internacionales, y desanima, por tanto, a los estados a reglamentar sus asuntos mediante acuerdos internacionales y someter sus controversias a la decisión de un tercero. Las incertidumbres en este campo son en gran parte responsables del tan verbalista estado actual de los asuntos internacionales, y de las sombrías perspectivas respecto a la creación de un orden mundial realizable y recomendable. La interpretación de los tratados, por tanto, requiere atención como el mayor problema de la comunicación humana en las relaciones jurídicas internacionales.

La interpretación de los tratados es una especie dentro de interpretación jurídica y, además, una aplicación particular de la interpretación en gene-

Tribunal surgieron de una discutida interpretación de un tratado. Esto ha sido así aun en los casos en que el carácter general del punto básico decidido por el Tribunal ha obscurecido por completo el elemento de la interpretación del tratado de que ha surgido". Véase también la Opinión Consultiva del Tribunal Internacional de Justicia sobre Certain Expenses of the United Nations (Article 17, Paragraph 2, of the Charter) de 1962, ICJ, Reports, 1962, 155, en donde el Tribunal "no encontró 'razón convincente' por la que no debiera dar la opinión consultiva que solicitó la Asamblea General", pues la solicitud invitaba al Tribunal "a emprender una tarea esencialmente judicial, a saber, la interpretación de la estipulación de un tratado".

6 En cuanto a varios factores responsables de la confusión en este campo, véase J. Stone "Fictional Elements in Treaty Interpretation - a study in the International Judicial Process", Sydney Law Review 1, 1953-54, pág. 346.

7 Cf. T.C. Yu, The Interpretation of Treaties, 1927, 72 , quien dice que estas reglas son tan abundantes que "la mera aplicación de una o la sagaz combinación de dos de ellas puede producir casi cualquier conclusión que el intérprete desee". Cf. también Lord McNair, op. cit., supra en la n. 1, pág. $3^{65}$. 
ral. En un sentido amplio, pero aún propio, toda conducta humana externa está sujeta a interpretación. ${ }^{8}$ En el campo del derecho, el estudio pertinente a la interpretación se distribuye bajo los títulos de interpretación de leyes, contratos (inclusive tratados) y testamentos. Pero, aun en el sentido jurídico, no es de ninguna manera inapropiado hablar de interpretación de todo acto juridicamente relevante. ${ }^{9}$ Siendo la interpretación un asunto humano omni-pertinente, es en realidad una actividad ilimitada, ya que la interpretación misma es un acto humano y como tal sujeta a interpretación, que, a su vez, está sujeta a interpretación, etc., ad infinitum. Sin embargo, para fines prácticos tiene que haber un límite en la interpretación. ¿Pero dónde está este límite? Hay una regla clásicá expresada por de Vattel como sigue: "La primera regla general de la interpretación es que no debe permitirse que sea interpretado lo que no necesita de interpretación." 10 La repetición de esta máxima fue considerada por Lord McNair como algo vacio y un poco exasperante, pues esa máxima es "en verdad una petitio principii, ya que da por resuelto el problema de saber si las palabras utilizadas son claras o no -y esto es un asunto subjetivo, ya que pueden ser claras para un hombre y no para otro $y$, frecuentemente, son claras para uno o más jueces, y no para sus colegas"'11

En términos de nuestro análisis del acto de comunicación humana, la interpretación juridica, como un ejemplo de tal comunicación, puede ser articulada como sigue: (1) lo interpretantum, o sea, el objeto de la interpretación (communicatum); (2) el autor de lo interpretantum (legislator); (3) el intérprete (commúnicator); (4) el enlace de la interpretación, o sea, la relación entre el autor de lo interpretantum y el intérprete (enlace de comunicación); (5) los principios y métodos de interpretación (medios de comunicación); (6) la situación de interpretación (situación de comunicación). Lo que se ha dicho arriba sobre los elementos del acto de la comunicación humana en

8 Véase E. Betti, Teoria Generale della Interpretazione, 1955, passim, quien ofrece un tratamiento comprensivo de la interpretación en diversos campos de la actividad humana. Véase también E. Garcia Máynez, Introducción al Estudio del Derecho, $8^{2}$ ed. 1958, 325, quien dice que "no sólo se puede interpretar la ley, sino, en general, toda expresión que encierre un sentido".

- Cf. Ch. de Visscher, Problemes d'Interpretation Judiciaire en Droit International Public, 1969, 9, quien dice que "dans la perspective du droit intenational public, la mission de l'interprétation est de fixer la signification juridique de tout comportement quelconque des Etats dans leur relations mutuelles". En cuanto a la necesidad de interpretar el derecho consuetudinario, véase $\mathbf{H}$. Mokre, Theorie des Gewohnheitsrechts, 1992, 176 . Véase también el Haya de la Torre Case, 1951, ICJ, Reports, 1951, 72, para la referencia a la solicitud hecha por el Gobierno de Colombia al Tribunal para interpretar su Sentencia en el Asylum Case. Sobre la interpretación judicial de las Opiniones Consultivas, véase S. Rosenne, The International Court of Justice, 1957, $4^{68-473 .}$

10 Vease de Vattel, Le Droit des Gens, ou Principes de la Loi Naturelle, Appliqués a la Conduite et aux affaires des Nations et des Souverains, 1758, II xvii, par. 263.

12 Véase Lord McNair, op. cit, suppra en la n. 1, pág. 379. Cf. Lauterpacht, op. cit. supra en la n. 5 , pág. $5^{2}$. 
general ${ }^{12}$ se aplica a los elementos correspondientes de la interpretación. Vamos a necesitar los conceptos así articulados para la discusión subsiguiente, como fundamentos de la argumentación.

El término "interpretación" ha sido empleado en estrecha conexión con algunos otros términos. Con el fin de evitar confusiones resulta necesario distinguir el significado de aquél del significado de éstos. Al hablar de la interpretación jurídica, la interpretación del derecho ha sido enlazada con la aplicación del derecho. Los términos y nociones respectivos se refieren a dos actividades estrechamente conectadas, pero con todo diferentes: mientras la interpretación del derecho se dirige al descubrimiento y formulación clara de normas jurídicas aplicables, la aplicación del derecho se dirige a inferir de las normas jurídicas así descubiertas o formuladas, normas juridicas indispensables más particulares, o a la calificación jurídica de un estado de cosas. Además, la interpretación ha sido enlazada con la construcción en el campo del derecho. Parece que los términos "interpretar" y "construir" han sido utilizados, y en muchas ocasiones pueden ser utilizados con propiedad, en forma intercambiable; sin embargo, diríase que el segundo es más apropiado cuando lo interpretantum está ordenado dentro de un contexto más amplio de significados descubiertos o asentados, cuyo establecimiento hace que lo interpretantum aparezca dentro de un todo sistemático. En la literatura juridica continental, la interpretación es aludida con frecuencia mediante el término "hermenéutica". ${ }^{13}$ El empleo de este término fuera de la teología es raro en la literatura anglo-americana. Por su origen lingüistico, "hermenéutica" se enlaza con el nombre del mensajero divino Hermes, en la mitología y religión griegas. De acuerdo con esto, "hermenéutica" es apropiado como un término plástico referente a la interpretación cuya mira es descubrir pensamientos ocultos, inescrutables o numinosos.

Alguna luz puede arrojarse sobre el significado de "interpretación" si consideramos el origen lingüístico de esta palabra. El Webster New International Dictionary ${ }^{14}$ la asocia con la palabra latina pretium (es decir: precio, valor). Por ende, las intuiciones lingüísticas conectadas con el significado de "interpretación" indican que la actividad correspondiente se ha concebido como una actividad evaluadora, apreciativa y tasadora. Que juicios de valor están involucrados en la interpretación jurídica u otra distinta, es manifiesto también conforme al uso actual del término.

De los obstáculos que existen para el adelanto intelectual en la interpretación de tratados, el primero que se destaca considerablemente, es: "¿cuál es el objeto de la interpretación de los tratados?". Hay una batalla permanente e indecisa entre los partidarios de làs teorías subjetivistas y objetivistas

12 Véase supra, cap. I, pág. 1.

13 Betti, op. cit. supra en la n. 8, cap. III.

14 Véase sub voce "Interpretation". 
de la interpretación; los primeros sostienen que lo interpretantum en la interpretación jurídica es la intención del legislador, mientras que los segundos afirman que es el significado objetivo (portée) de las expresiones jurídicas. Cada una de estas opiniones suscita una cantidad de intrincados problemas peculiares suyos. Los defensores de la teoría subjetivista están confundidos por la pregunta: ¿cuál es el alcance preciso de la intención (o voluntad) del legislador, especialmente en los casos en que un precepto legal resulta de la colaboración de numerosas personas e instituciones? ${ }^{15}$ Particularmente la postulación de una voluntad o intención colectivas es objeto de fuertes objeciones. Los defensores de la teoría objetivista tampoco hallarían cómoda su posición si fueran desafiados por :la pregunta: ¿cuál es el alcance exacto del significado objetivo de las expresiones jurídicas, y con qué criterios puede juzgarse la objetividad de este significado? Además, esta teoría parece ser objetable sobre la base de que posiblemente expone una ley dada a las vicisitudes de las variables opiniones politicas y a la ocasionalidad de las cambiantes posiciones del poder político. ${ }^{16}$ Ambas teorías desarrollan sus batallas en las tenebrae de la psicologfa y de la semántica en los campos correspondientes.

Los problemas relativos al autor de lo interpretantum adquieren una agudeza particular en el contexto de la teoría subjetivista de la interpretación. ¿Quién es, exactamente, el autor de la ley cuya intención o voluntad debe prevalecer? En el caso de un tratado, ¿es la autoridad que ratifica, o son los que negociaron el tratado, o los que lo proyectaron, o todos ellos? E1 asunto sería relativamente sencillo si pudiéramos asumir que la coincidencia de la voluntad de una, de varias o de todas las clases de estas personas es significativa. Pero, ¿podemos sostener tal suposición? Esto es muy discutible, en vista del hecho de que las reservas mentales, las concepciones erróneas sobre el objeto de la reglamentación jurídica, o la ausencia absoluta de ideas sobre tal objeto, juegan escaso papel, si no es que ninguno -en la validez de las leyes que surgen de los procedimientos parlamentarios o de convenios internacionales que resultan de los procedimientos para concluir tratados. ${ }^{17}$

En lo que mira al intérprete, se está de acuerdo generalmente en que las interpretaciones obligatorias en sentido propio sólo pueden emanar de las autoridades competentes para aplicar la ley dada. Las interpretaciones que vienen de los legisladores mismos en el procedimiento legislativo idóneo,

15 Cf. H. Silving, "A Plea for a Law of Interpretation", University of Pennsylvania Law Review, 98, 1949-50, 499, quien en la pág. $5^{10}$ dice que "un 'intento colectivo' a la luz de la psicologia moderna no es un concepto tan irreal como los juristas explican que es". Sin embargo, admite que "aún queda el problema de alcanzar o expresar tal intento por métodos juridicos eficaces".

18 Cf. ibid., 508.

17 Cf. A. Hägerström, Inquiries into the Nature of Law and Morals (ed. de K. Olivecrona, trad. de C. F. Broad, 1953), 18-35, 55, 250, para una crítica incisiva de la teoria de la voluntad. 
las llamadas interpretaciones auténticas, no son propiamente interpretaciones, sino más bien nuevos preceptos legislativos, que en parte dan una nueva forma a la ley existente y en parte la desarrollan. Las llamadas interpretaciones doctrinales no son más que opiniones académicas concernientes a lo interpretantum y tienen, por lo tanto, sólo valor persuasivo, que puede determinar de facto, pero no de jure, interpretaciones con fuerza obligatoria. Sin embargo, la materia no es tan sencilla como parece serlo en este punto. Existe el problema de si la idónea autoridad interpretativa tiene también competencia para interpretar praeter legem y contra legem, y de cuáles son los límites exactos de una interpretación intra legem, si se niega tal competencia. ${ }^{18}$ ¿Puede el intérprete extender también la ley? ${ }^{19}$ y si es así, ¿hasta qué grado y dentro de qué límites? Existe otro problema más: ‘tiene el intérprete autoridad para determinar el curso y contenido de interpretaciones futuras y, si es así, en qué sentido y hasta qué grado? ¿Qué intérprete, si es que hay alguno, tiene tal autoridad?

En lo que mira al enlace entre el intérprete y el autor de lo interpretantum surgen problemas molestos cuando la politica de la autoridad legislativa y de la autoridad interpretativa han llegado a discrepar considerablemente. ¿Tiene el intérprete que respetar siempre y bajo cualquier circunstancia los juicios políticos de las autoridades políticas del momento? ¿O puede hacerlas a un lado y dar fuerza sólo a las consideraciones políticas del autor de lo interpretantum? ¿O debería buscar un compromiso feliz entre ambos? y, si es así, ¿cómo puede hacer esto si las consideraciones políticas de que se trata son diametralmente opuestas unas a otras? ¿Se permite al intérprete usar su propio juicio, el cual puede, sobre la materia en cuestión, discrepar de lo que el autor de lo interpretantum se proponía comunicar, o de lo que el poder político del momento quiere imponer? Parece haber general acuerdo sobre que el intérprete puede, hasta cierto grado, usar su propio juicio. Pero, si es así, ¿hay también espacio para lo que se ha llamado "las sanas audacias del intérprete", 20 o sea, para su propio juicio independiente, justificable sobre bases distintas de las jurídicas o del poder político? En el plano internacional surge un problema especial por el hecho de que los estados pretenden tener el derecho de interpretar los tratados de que son partes. ¿Cuáles son los procedimientos adecuados para conciliar las interpretaciones en conflicto, que así se producen, especialmente cuando al menos una de las partes contratantes rehusa someterse a la decisión de un tercero?

18 Véase Betti, op. cit., supra en la n. 8, en cuanto al "canon hermenéutico fundamental", de acuerdo con el cual "sensus non est inferendus, sed efferendus". El canon que dijera que el significado no debe ser introducido en el texto, sino extraido del mismo, autorizaria sólo la interpretación estrictamente intra legem.

18 Para una respuesta afirmativa a esta cuestión, véase en Stone, artículo citado supra en la n. 6, págs. $363-68$.

20 Véase L. Recaséns Siches, Nueva Filosofia de la Interpretación del Derecho, 1956, 163. 
Para la práctica jurídica quizás los problemas más molestos han surgido en el campo de los principios y métodos por medio de los cuales debe determinarse lo interpretantum. La aplicación de los llamados cánones de interpretación ha mostrado que pueden conducir a resultados ampliamente divergentes. A menudo parecen "neutralizarse" unos a otros ${ }^{21}$ por la producción de juicios incompatibles entre ellos. Así, los medios de interpretación producen antinomias. Parece que no existen principios y métodos superiores a los que uno recurriera para poder resolver las antinomias y llegar a soluciones concluyentes unívocas partiendo de los adiaphora del sic et non. ${ }^{22}$

Finalmente, en lo que mira a la situación de la interpretación, surgen problemas especiales bajo este respecto a causa del hecho de que todo en el mundo está sujeto al cambio. Se hace cada vez más difícil determinar las intenciones de los legisladores, a medida que transcurre el tiempo, no sólo porque posiblemente los documentos pertinentes no estén ya a nuestra disposición, sino también, y especialmente, porque resultaría muy difícil para el intérprete repensar las situaciones pasadas, en la misma forma en que los autores de lo interpretantum las habían pensado. ${ }^{23}$ Además, al transcurrir el tiempo, tienen lugar cambios en los significados de las palabras y dentro del contexto general del orden jurídico contemporáneo una ley puede tomar un significado y un sentido muy distintos de los que razonablemente haya tenido en otra época. Si Ia interpretación está, por tanto, determinada por una situación y sujeta a cambios del "clima" político, cultural y jurídico, ¿cómo puede asegurarse su debida continuación, y cómo podremos alejarla del capricho del cambio de los tiempos y de la arbitrariedad de los juicios acerca de los cambios pertinentes? ¿Debería el intérprete buscar absolutamente la continuidad de la interpretación, o deberia más bien dejarse llevar por la corriente del flujo del tiempo?

Ya hemos formulado suficientes preguntas para preocuparnos bastante por los problemas con que se enfrenta la interpretación de los tratados. Las preguntas formuladas no tienen la pretensión de agotar la materia, sino que sólo tratan de señalar los temas sobresalientes. Quizás existen en el campo que ahora nos preocupa más complicaciones de las que hemos llegado a descubrir. Se puede dudar que logremos construir caminos en la región aporética de la interpretación de los tratados. Pero lo que seguramente podemos hacer es aclarar hasta cierto grado la naturaleza de sus aporiae y buscar los medios que nos permitan operar en ella. Antes de aventurarnos a esta tarea, estudiaremos en los dos capítulos siguientes en qué forma los tribunales y

21 Véase Silving, artículo citado supra en la n. 15, pág. 522.

22 Cf. Stone, artículo citado supra en la n. 6, pág. 360; C. Fairman, "The Interpretation of Treaties", Transactions of Grotius Society 20, 1935, 123, en las págs. $134^{-1} 35$.

23 Cf. Betti, op. cit. supra en la n. 8, págs. 894-35, quien cita a Montaigne, Essais, 11 , xii: "Les loix prennent leur auctorité de la possesion et de l'usage: elles groissent et s'annoblissent en roulant, comme nos riviéres". 
los juristas internacionales han abordado los problemas que nos preocupan aquí, y qué han logrado en el camino hacia su solución.

2. Los principios de la interpretación de los tratados, y los tribunales internacionales

En forma de una colección no sistematizada de sabiduría, los principios de la interpretación jurídica han llegado hasta nosotros desde las doctrinas del derecho romano clásico. Todos los sistemas jurídicos contemporáneos han aprovechado esta fuente, sea directamente o por mediación de los civilistas continentales. ${ }^{24}$ Así, para la aplicación del derecho internacional, se halla a nuestro alcance un cuerpo de normas de origen común, con el que están familiarizados los juristas de todas las nacionalidades, y del cual han hecho uso constante. ${ }^{25}$ Dentro del marco de este cuerpo general de normas ha habido un margen considerable para un juego de escondite intelectual, debido al carácter no-sistematizado de las normas, sus ambigüedades y su flexibilidad (como con todas las normas de sabiduría), que permite su adaptación a las circunstancias que requieren sus servicios. Formulaciones comprensivas y más o menos coherentes de ellas, como la de Vattel, por ejemplo, no han logrado cambiar su carácter lógico o semántico. Pero tales formulaciones han provisto a los tribunales internacionales de puntos de partida para proceder, desde ellos, a la búsqueda de soluciones bien razonadas de los problemas que implican una interpretación de tratados. Además, estas formulaciones han ayudado a los tribunales a suprimir o reducir la sospecha de que tal interpretación carece de principios, y es materia de juicios concretos discrecionales, "tychisticos", impredecibles y erráticos.

Los tribunales internacionales han tratado los principios de la interpretación cuando éstos han requerido su atención en conexión con problemas particulares que fueron llevados ante ellos. Como en todo caso de derecho precedencial, un sistema de principios asi tratados no puede ser una meta establecida de la labor judicial. Sólo puede serlo un producto secundario de su trabajo; o quizá una idea vagamente orientadora que puede materializarse

24 En cuanto a las relaciones entre la interpretación juridica romana y anglo-americana, véase A. A. Schiller, "Roman Interpretation and Anglo-American Interpretation and Construction", Virginia Law Review 27, 1940-41, 733-768.

25 Para la historia de la interpretación juridica en los clásicos del derecho internacional, véase L. M. Bentivoglio, La Funzione Interpretativa nell'Ordinamento Internazionale, 1958, 32-42. Un notable capítulo, titulado "De Interpretatione" puede hallarse en Grotius, De Jure Belli ac Pacis, II, xvi. Los siguientes pensamientos claves de Grotius merecen citarse aqui: "Rectae Interpretationis mensura est collectio mentis ex signis maxime probabilibus. Ea signa sunt duum generum, verba et conjecturae aliae, quae aut seorsim considerantur, aut conjunctim." "In fide quid senseris, non quid dixeris cogitandum." "Si nulla sit conjectura quae ducat alio, verba intellingenda sunt ex proprietate, non grammatica quae est ex origine, sed populari ex usu." 
o no en forma de una doctrina definida. Ya que el derecho internacional no conoce la doctrina de los precedentes obligatorios, las condiciones para desarrollar tal sistema son inclusive peores aquí, que bajo el common law de Inglaterra, por ejemplo; pues cada nuevo creador de decisiones judiciales internacionales puede sentirse totalmente libre para deshacer lo que sus predecesores han efectuado en orden al establecimiento de una norma. Sin embargo, los tribunales internacionales han hecho una cantidad de formulaciones notables sobre las reglas de la interpretación en su aplicación a los tratados. Estas formulaciones requieren nuestra atención para ver cuál puede ser su contribución para una mejor inteligencia de los problemas de la interpretación de los tratados, y para un viaje más seguro por la región, aparentemente "desprovista de caminos", a que el estudioso es conducido por su tentativa racional de dominar estos problemas. De la masa de material que los tribunales internacionales han elaborado en relación con los asuntos de la interpretación de tratados, seleccionaremos algunos pensamientos representativos acerca de los principales problemas en este campo. Un muestrario de estos pensamientos nos puede ofrecer una base para discutir las deliberaciones de L'Institut de Droit International sobre la interpretación de los tratados, y para formar nuestros propios puntos de vista acerca de sus aporiae.

Los tribunales internacionales han tenido ocasiones para reflexionar sobre su propia actividad en el campo de la interpretación de los tratados, haciendo ciertas declaraciones sobre la extensión y los límites de esta actividad. ${ }^{26}$ Así, en la Opinión Consultiva sobre la Interpretación de Tratados de Paz (Segunda Fase) (1950), la Corte Internacional de Justicia dijo:27 "Es deber de la Corte interpretar los tratados, no revisarlos." Este dictum fue reiterado por la Corte en la Sentencia sobre Derechos de Estadounidenses en Marruecos (1952).28 Mediante estas declaraciones la Corte quiso acentuar que su actividad de intérprete sólo puede ser intra legem, y bajo este concepto no puede efectuarse una legislación judicial. Sin embargo, tales declaraciones no garantizan que de hecho no se hagan interpretaciones praeter e inclusive contra legem, y que los tribunales internacionales hayan logrado hacer visible en los casos decididos y reconocible para futuros casos la intangible línea divisoria entre la interpretación de los tratados y la legislación judicial. ${ }^{29}$ Con referencia a la extensión y los límites de su actividad en la interpretación de tratados, los tribunales han acentuado también que su interpretación sólo

26 Para una visión amplia del trabajo del Tribunal Internacional de Justicia en el cam. po de la interpretación de los tratados, que abarca el periodo hasta 1958, véase J. F. Hogg, "International Court: Rules of Treaty Interpretation", 1958-59, 43 Minnesota Law Review $43,1958-59,369-441$, y la misma publicación, vol. 44, 1959-60, 5-73. Estos artfculos serán referidos más adelante de esta manera: "Hogg, artículo I" y "Hogg, artículo II".

27 Véase ICJ, Reports, 1950, 229.

28 Véase op. cit., 1952, 196.

29 Cf. G. Schwarzenberger, International Law I (9 $9^{\text {a }}$ ed. 1957), 488. 
puede ser ex tunc, o sea, estableciendo los efectos jurídicos del tratado como eran en el tiempo de concluirse éste, y no ex nunc, o sea, como pudieran y debieran ser en el momento de la interpretación. Así, la Corte Permanente de Justicia Internacional dijo en su Opinión Consultiva sobre el Acceso a las escuelas alemanas de minorias (1931) ${ }^{30}$ que "debe considerarse que los términos de la convención han ostentado siempre el significado que se les asigna mediante esta interpretación". Aquí, de nuevo, uno puede preguntarse si las declaraciones de los tribunales, al respecto, son algo más que la expresión de deseos piadosos o de tentativas para dar alguna seguridad y facilidad a los litigantes, fachada trás de la cual puede aún hacerse una interpretación $e x$ nunc. Pues ¿con qué criterios es posible siempre comprobar que una convención ha "ostentado siempre el significado" que se le asigna mediante una interpretación? 31

Parece que los tribunales internacionales no se han formado una opinión sobre el punto de cuál es el objeto de la interpretación de los tratados. En el Caso de la Isla de Timor (1914), ${ }^{32}$ la Corte Permanente de Arbitraje dijo que "aquí una vez más, y siempre, debemos buscar la intención real y armoniosa de las partes en el momento de obligarse a sí mismas". La misma idea fue también expresada por la Corte Permanente de Justicia Internacional en el Caso Mosul (1925). ${ }^{33}$ Sin embargo, en la sentencia sobre el Caso del estatuto del territorio de Memel (Méritos) (1932) ${ }^{34}$ el mismo tribunal sostuvo la idea de que el objeto de la interpretación era algo que tenía una existencia objetiva en el texto del tratado mismo. Opiniones similares han sido expresadas por la Corte Internacional de Justicia en la Opinión Consultiva sobre la Competencia de la Asamblea General para la admisión de un Estado en las Naciones Unidas (1950) y en la Opinión Consultiva sobre las Reservas a la Convención en cuanto al Genocidio (1951).55

Existe una regla bien conocida, de acuerdo con la cual se debe dar fuerza a los "términos simples" de un tratado, o sea, que las palabras de un tratado deben interpretarse en vista de su "significado general y ordinario", o de su "significación natural", etc., sin buscar aliunde un significado "cuando los términos son claros".36 Esta regla jugó un papel en la Opinión Consultiva de la Corte Permanente de Justicia Internacional sobre el Intercambio de

30 Véase PCIJ, Series A/B 40, pág. 16.

$31 \mathrm{La}$ interpretación ex nunc entra dentro de las decisiones de los tribunales internacionales, sobre todo a través de su admisión de consideraciones equitativas. Cf. Schwarzenberger, op. cit. supra en la n. 29 .

32 Véase Bureau International de la Court Permanente d'Arbitrage, publicación del Island of Timor Case, 1914, 18.

33 Véase PCIJ, Serie B I2, pág. ig.

34 Véase PCIJ, Serie A/B 49, pág. 316.

35 Véase respectivamente ICJ, Reports, 1950,18 y 1951, 53 .

36 Para el enunciado de esta regla, véase McNair, op. cit., stupra en la n. 1, pág. $3^{66}$. Ce. de Vattel, op. cit. supra en la n. 10, 11, xvii, par. 271. 
Las Poblaciones Griega y Turca (1925). La Corte debía determinar el significado de las palabras "habitants... établis" en el Artículo 2 de la Convención al respecto y consideró que "con el fin de decidir lo que constituye un habitante establecido", era necesario "basarse en el significado natural de las palabras". La Corte pensaba que, de acuerdo con su significado natural, la palabra "établis" se refería a "una situación de hecho, constituido en el caso de las personas en cuestión, por una residencia de naturaleza duradera". ${ }^{37}$ En su Opinión Consultiva sobre el caso de la "Interpretación de la Convención sobre el Empleo de las Mujeres durante la Noche" (1932) la misma Corte tuvo la oportunidad de formular una restricción a la regla "de los términos simples", diciendo que esta regla tenía el sentido de una significación primaria, pero que es posible apartarse del "sentido natural de las palabras". Para hacer esto, sería "necesario encontrar algún motivo válido para' interpretar la disposición de manera diferente". ${ }^{38}$ Que la regla en cuestión rige primariamente, pero puede ser denegada, se expresa también en la Opinión Consultiva de la Corte Internacional de Justicia sobre las Condiciones de Admisión de un Estado para ser Miembro de las Naciones Unidas (Artículo 4 de la Carta) (1948). Dice la Corte: "Para autorizar una interpretación distinta de la que resulta del significado natural de las palabras, se necesitaría una razón decisiva", que "no se ha establecido" en el caso presente.39

37 Véase PCIJ, Serie B 10, pág. 20, 26. Cf. la Opinión Consultiva del mismo año sobre el Polish Postal Service in Danzig, Serie B 11, pág. 37, en donde el mismo Tribunal sosturo que los términos en cuestión "tienen que ser interpretados en su sentido ordinario".

38 En el caso presente no fue encontrado por el tribunal tal fundamento. Véase PCIJ, Serie A /B 50, pág. 373. Cf. la Sentencia del mismo tribunal, de 1933, sobre el Legal Status of Eastern Greenland, Serie A/B 53, pág. 49, en donde sobre el significado de la palabra "Greenland" el Tribunal dijo que "si se alega por una de las partes que ha de atribuirse a aquélla algún significado insólito o excepcional, le corresponde a esa parte fundar su pretensión". Y cf. la Opinión Consultiva del mismo Tribunal sobre la Acquisition of Polish Nationality, Serie $\mathrm{B} 7$, pág. 20 , donde hizo una declaración todavía más resuelta: "Ante una cláusula que deja poco qué desear en el aspecto de la claridad, es forzoso aplicar esta cláusula como está, sin considerar si podrian haberse añadido con ventaja o sustituido por ella otras estipulaciones."

39 Véase ICJ, Reports, 1947-48,63. El mismo Tribunal dijo en su Opinión Consultiva de 1959 sobre la Competence of the General Assembly Regarding Admission to the United Nations, que "el primer deber de un tribunal que es llamado para interpretar y aplicar la estipulación de un tratado, es esforzarse por dar valor a los términos en su significado natural y ordinario dentro del contexto en que aparecen. Si las palabras pertinentes, en su significado natural y ordinario producen sentido en su contexto, ése es el fin del asunto. $\mathrm{Si}$, por otra parte, las palabras en su significado natural y ordinario son ambiguas o con. ducen a un resuitado irracional, entonces, y sólo entonces, el Tribunal, rccurriendo a otros métodos de interpretación, tienc que procurar asegurarse de aquello que las partes realmente quisieron decir, cuando usaron las palabras". Véase ICJ, Reports, 1950, 4.

Puede notarse que en la reciente Opinión Consultiva del Tribunal Internacional de Justicia de 1962 sobre Certain Expenses of the United Nations (Article 17, Paragraph 2, of the Charter), ICJ, Reports, 1962, 160, el Tribunal consideró "el significado llano del texto" como uno de los criteria decisivos de la interpretación de la estipulación de que se trata. Para un análisis del razonamiento del Tribunal en este caso, que "resume hasta 
Aparte de la atenuación a la regla de los "términos llanos", mencionada arriba, resultó muy claramente de la labor de los tribunales internacionales que esta regla es atenuada además por el requisito de que debe entenderse en conexión con otra regla, de acuerdo con la cual las palabras de un tratado no deberían interpretarse en forma aislada, sino tomando en consideración el contexto total del tratado. Así, en la Opinión Consultiva sobre la Competencia de la Organización Internacional del Trabajo con respecto al trabajo y Producción Agricola (1922), la Corte Permanente de Justicia Internacional observaba que "es obvio que el Tratado debe entenderse como un todo, y que su significado no debe determinarse meramente de acuerdo con frases particulares, que, separadas del contexto, pueden interpretarse en más de un sentido". La Corte también dijo que "el contexto es el criterio definitivo, y en el presente caso la Corte debe considerar la posición en que se encuentran estas palabras y el sentido en que son empleadas en la Parte XIII del Tratado de Versalles." 40 En su sentencia sobre la Interpretación del Estatuto de Memel, la misma Corte dijo que "la Convención de París de 1924 y el Estatuto anexado a ella deben considerarse como un todo para poder comprender el régimen que los Cuatro Poderes y Lituania pretendían establecer para el Territorio de Memel". ${ }^{41}$ Quizás la formulación más clara que la Corte ha hecho sobre esta materia puede encontrarse en su Sentencia sobre la Desviación del Agua del Rio Mosa (1937): "El Tratado dio existencia a un régimen determinado que resulta de todas sus disposiciones en conjunto. Forma un todo completo, cuyas diversas estipulaciones no pueden ser disociadas de las otras y consideradas independientemente por si mismas." "42

Lo que los tribunales dicen sobre las relaciones entre la regla de los "términos llanos" y la del "contexto total", parece ser, como lo ha expuesto Julius Stone, que la disposición de un tratado tiene un significado "llano" si la "disposición ha sido entendida en su contexto, incluyendo en él la intención general o finalidad del tratado entero, tan manifiestas como se pueda descubrir en la evidencia de la intención de las partes". ${ }^{43}$ Sin embargo, esta formulación, aun cuando puede ser un resumen aceptable de las realizaciones de los tribunales internacionales sobre la materia en cuestión, es apenas algo

la fecha la práctica" del Tribunal Internacional de Justicia y de su predecesor sobre algunos aspectos de la interpretación de los tratados, véase J. F. Hogg, "Peace-Keeping Costs and Charter Obligations - Implications of the International Court of Justice Decision on Certain Expenses of the United Nations", Columbia Law Review 62, 1962, 1230, págs. 1241. 1247 .

40 Véase PCIJ, Serie $\mathrm{B} 2$ \& 3, pág. 23. Cf. Serie A/B 70, págs. 21-23.

41 Véase PCIJ, Serie A/B 49, pág. 312. En el Free Zones Case, el mismo Tribunal dijo que "el Artículo 435, tanto por razón de su posición en el Tratado de Versalles, como por su origen, forma un todo completo: sería imposible, por tanto, interpretar el segundo parágrafo sin atención al primero". Serie A/B 46, pág. 140.

42 Véase $\mathrm{PCIJ}$, Serie A/B 7o, pág. 21.

43 Véase Stone, artículo citado supra en la n. 6 , pág. 357, n. 65 a. 
más que una ilustración de problemas ulteriores. Pues aún permanece indeterminado qué es exactamente el contexto total. Así surgió un desacuerdo en el Caso de Ambatielos (Objeción preliminar) (1952) sobre si los documentos que acompañan un tratado forman parte de él $\mathrm{y}$, por lo tanto, si forman parte del contexto que debe tomarse en cuenta para la interpretación del tratado correspondiente.44

Tomando la regla de los "términos llanos" como la que ofrece al intérprete de un tratado una base inicial, notamos que esta base es debilitada por otra regla que se encuentra en antagonismo con la de los "términos llanos", o sea, la de la eficacia, formulada habitualmente como "Ut res magis valeat quam pereat".45 George Schwarzenberger ha caracterizado esta máxima como "el grito de batalla de la interpretación funcional". ${ }^{46} \mathrm{Su}$ idea básica reside en la necesidad de evitar los resultados absurdos que produciría una interpretación estrictamente literal de las palabras. Basándose en el recurso al argumentum ad absurdum, esta regla debe producir una interpretación liberal de las palabras utilizadas en un tratado. La atenuación a la regla de los "términos llanos" que resulta así, es formulada por la Corte Permanente de Justicia Internacional en su Opinión Consultiva sobre el Servicio Postal Polaco en Danzig (1925), en donde la Corte dijo: "Es un principio cardinal de la interpretación, que las palabras deben ser interpretadas en el sentido que tendrían normalmente en su contexto, a menos que tal interpretación nos conduzca a algo irracional y absurdo." 47 La misma idea fue expresada por la Comisión Anglo-Americana de Reclamaciones en la Reclamación de los indios Cayuga,48 en donde la Corte dijo: "Nada se ha establecido mejor como canon de interpretación en todos los sistemas jurídicos, que el siguiente: una cláusula debe interpretarse en una forma que ofrezca un significado más bien que en otra que lo prive de sentido." La regla de la eficacia fue uno de los principales fundamentos de la argumentación en la Opinión Consultiva de la Corte Internacional de Justicia sobre la Indemnización de Lesiones Sufridas en el Servicio de las Naciones Unidas (1949), señaladamente sobre el punto de que las Naciones Unidas pudieran reivindicar daños por la muerte o lesiones de uno de sus funcionarios. La Corte observó que era imposible ver cómo las Naciones Unidas podrían hacer esto "a no ser que poseyeran facultad para presentar una reclamación internacional" contra el

44 Véase ICJ, Reports, 1952, 42, 49, 60, 64, 70 .

45 La regla ha sido descrita por el Juez de Visscher como sigue: "Las cláusulas de un tratado tienen que ser no sólo consideradas como un todo, sino también interpretadas de manera que eviten cuanto sea posible privar a una de ellas de fuerza práctica en beneficio de las otras." Véase la Opinión Consultiva del Tribunal Internacional de Justicia sobre el International Status of South-West Africa, 1950, discrepando el Juez de Visscher, ICJ, Reports, 1950, 187 .

46 Véase Schwarzenberger, op. cit. supra en la n. 29, pág. 520.

47 Véase PCIJ, Serie B 11 , pág. 39.

48 Véase American Journal of International Law 20, 1926, 587 . 
Estado responsable. Las Naciones Unidas deben tener el poder de hacer esto, aun cuando tal poder no haya sido conferido expresamente por la Carta. ${ }^{40}$ Esto se parece mucho a una interpretación praeter legem, que, como hemos visto al comienzo de este capítulo, los tribunales internacionales no estaban muy dispuestos a permitir. Poco después de la decisión en el Caso de Indemnización por Lesiones, la misma Corte tuvo una oportunidad para mostrar que la máxima de $u$ tres magis valeat quam pereat sufre algunas limitaciones en su aplicación. En su Opinión Consultiva sobre la Interpretación de los Tratados de Paz con Bulgaria, Hungria y Rumania (Segunda Fase) (1950), declaró: "El principio de interpretación expresado en la máxima: ut res magis valeat quam pereat, frecuentemente citado como regla de la eficacia, no puede justificar que la Corte atribuya a las disposiciones para la conciliación de controversias en los Tratados de Paz un significado que... sería contrario a su letra y espíritu." 50

La regla de efectividad impulsa a una explicación liberal o a una interpretación extensiva de los textos legales. Este efecto (que también puede resultar de la aplicación de otras reglas de interpretación) es frenado 1 por principios específicos que exigen una interpretación restrictiva en los casos en que pueda mostrarse que están implicados. El más elevado entre estos principios es la soberanía de los Estados. Así, en la Sentencia del Caso Lotus, la Corte Permanente de Justicia Internacional dijo en 1927: "No pueden presumirse restricciones a la independencia de los Estados." 52 En el Caso de las Zonas Libres (1929), la misma Corte dijo que "en caso de duda, una limitación de soberanía debe interpretarse restrictivamente".53 Que el principio en cuestión es subordinado lo señaló la Corte Permanente de Justicia Internacional en El Caso Wimbledon (1923), en el cual admitía que, en caso de duda, las limitaciones al ejercicio de la soberania deberían ser interpreta-

49 Véase ICJ, Reports, 1949, 174.

50 Véase ICJ, Reports, 1950, 221. Cf. Lauterpacht, op. cit., supra nota 5, pág. 292, quien señala que "en esencia" la regla de la efectividad "no es otra cosa que un requerimiento de buena fe. Pero la fuena fe no requiere otra cosa sino que se dé fuerza, de una manera equitativa y razonable, a la intención de las partes".

51 Una razón que disminuye la fuerza constrictiva de la regla en cuestión, es que los tratados no siempre se proyectan con precisión meticulosa. Como señala James Hogg, "el hecho de que el proceso del proyecto requiere asmenudo numerosos cambios antes de que se obtenga un texto definitivo, y de que en el proceso frecuentemente se han pasado por alto modificaciones necesarias, tiende a disminuir la fuerza constrictiva de la regla". Véase Hogg, artículo II, citado supra en la n. 26, pág. 11.

52 Véase PCIJ, Serie A 10, pág. 18.

53 Véase PCIJ, SerieA/B, pág. 167. En cuanto a otros principios, además del principio de soberania, que los tribunales internacionales hallaron para realizar una interpretación restrictiva, puede mencionarse uno, de acuerdo con el cual los derechos de un tratado que se otorgan a un Estado deben interpretarse de manera que no puedan derogar las reglas del derecho consuetudinario internacional. Véase la Sentencia del Tribunal permanente de Justicia Internacional sobre German Interests in Polish Upper Silesia (Merits), 1926, PCIJ, Serie A 7, págs. 21-22. 
das restrictivamente, diciendo empero que "se sentía obligada a detenerse en el punto en donde la llamada interpretación restrictiva fuese contraria a los términos llanos del artículo y destruyese lo que habia sido claramente concedido". 54

Para los que piensan que la meta de la interpretación de los tratados es la comprobación de la intención de las partes, sería un grato apoyo para su argumentación que los tribunales internacionales afirmasen la admisibilidad de los trabajos preparatorios. Por otra parte, la negativa por parte de estos tribunales de esa admisibilidad, reforzaría la suposición de los que piensan que la meta suprema de la interpretación de los tratados es la comprobación de su significado objetivo. En lo que mira a la Corte Permanente de Justicia Internacional y a la Corte Internacional de Justicia, éstas han mostrado cautela al expresar opiniones en estas materias, tratando de evitar una respuesta clara y definida sobre si los trabajos preparatorios son admisibles, y cuándo. Las siguientes sentencias ilustran esta actitud.

En el Caso Mosul (concerniente a la interpretación del artículo 3 (2) del Tratado de Lausanne) la Corte Permanente de Justicia Internacional dijo en 1925: "Como la Corte es de. opinión que el artículo 3 en sí mismo es suficientemente claro para que permita determinar la naturaleza de la decisión que el Consejo debe tomar en los términos de este artículo, no se presenta el problema de si la consideración del trabajo realizado en la preparación del Tratado de Lausanne (les travaux préparatoires) habría conducido también a la conclusión arriba formulada." 55 En el Caso Lotus, la Corte dijo en 1927 que "no hay caso de tomar en consideración el trabajo preparatorio, si el texto de una convención es suficientemente claro en sí mismo".56 El mismo año, en el Caso de la Comisión Europea del Danubio, la Corte reconoció la importancia de los trabajos preparatorios, diciendo que "el trabajo preparatorio confirma plenamente la conclusión a que la Corte ha llegado ahora", pero señaló que este trabajo preparatorio "no debería ser utilizado con el fin de modificar el significado llano del texto". 57 La Corte Internacional de Justicia, en la Opinión Consultiva sobre la Competencia de la Asamblea General para la Admisión de un Estado en las Naciones Unidas (1950), después de no encontrar "ninguna dificultad para establecer el significado natural y ordinario de las palabras en cuestión", era de opinión que "no es lícito, en el caso, recurrir a los travaux préparatoires".58 Estas declaraciones indican que los tribunales internacionales no están demasiado dispucstos a admitir los trabajos preparatorios como ayuda para la

54 Véase PCIJ, Serie A 1, pág. 24.

55 Véase PCIJ, Serie B 12, pág. 22.

50 Véase PCIJ, Serie A 10, pág. 16.

57 Véase PCIJ, Serie B 14, págs. 28, 31. Cf. Serie A/B 5o, pág. 380.

58 Véase ICJ, Reports, 1950, 8. 
interpretación de los tratados, pero que no han querido tampoco excluirlos totalmente.50

El breve examen anterior indica que lo expresado por los tribunales internacionales sobre los principios de interpretación de los tratados sólo equivale a un comienzo de cierto ordenamiento de estos principios, pero no a una doctrina judicial definida o a un ordenamiento sistemático de ellos.60 Lo que los tribunales han declarado en casos particulares puede ser muy valioso para cada caso particular en cuestión, o para los casos que puedan ser considerados como similares al caso particular. Sin embargo, toda generalización de la visión particular de los tribunales sobre materias de la interpretación de los tratados sería una empresa aventurada; seguramente no puede considerarse como una tarea ya realizada por los tribunales internacionales. En este estado de cosas habfa verdadera necesidad de un cuerpo erudito compuesto de estudiosos del derecho internacional de la más alta categoría para que interviniera y ejecutara esfuerzos intensivos para escudriñar y aclarar las materias no determinadas por los tribunales internacionales, en el campo de la interpretación de los tratados. Esta necesidad fue reconocida y el desafío de estos problemas aceptado por L'Institut de Droit International, que colocó la interpretación de los tratados en su agenda de las conferencias que tuvieron lugar en $195^{\circ}, 195^{2}$ y $195^{6}$.

\section{Deliberaciones y Resoluciones de L'Institut de Droit International sobre los Principios de la Interpretación de los. Tratados}

L'Institut de Droit International inauguró sus deliberaciones sobre el

\footnotetext{
59 En cuanto a las razones para vacilación judicial en materia de los travaux preparatoires, véase Lauterpacht, op. cit. supra, nota 5, págs. 127-136. Como primera razón menciona "el punto de vista de que el recurso al trabajo preparatorio, aunque afín a la llamada 'Escuela Ideológica Continental', es contrario a la práctica anglo-americana". Y considera este punto de vista como de importancia decreciente (pág. 127). Ráones más poderosas para esta vacilación se hallan en la "consideración de razones económicas en el trabajo del Tribunal" (págs. 130-134) y por el hecho de que es cuestionable si el trabajo preparatorio es en realidad aplicable al descubrimiento de la intención de las partes o si, al menos, facilita este descubrimiento en vez de hacerlo más difícil o aun de frustrarlo (págs. 134-36).

60 Existe naturalmente, para los escritores eruditos, algún propósito en usar los dicta de los tribunales internacionales relativos a la interpretación de los tratados, como un material bruto en la construcción de un conjunto sistemático de principios de esa interpretación. Sobre un notable intento de esta clase, véase Sir Gerald Fitzmaurice, "The Law and Procedure of the International Court of Justice 1951-4: Treaty Interpretation and Other Treaty Points", British Year Book of Internacional Law 33, 1957, 209., págs. 210-12. Véase también la formulación de Charles de Visscher sobre la regla fundamental de la interpretación de los tratados: "Le texte droit être compris selon l'acceptation usuelle de ses termes, dans son contexte et à la lumière de son object et de son but." de Visscher, op. cit, supra, nota 9, pág. 51. Tales ordenamientos sistemáticos de las reglas de la interpretación de los tratados pueden quizá entenderse dentro de la expresión de los puntos de vista de los tribunales internacionales sobre la interpretación de los tratados, pero no ser entendidos fuera de la expresión de esos puntos de vista.
} 
problema de la interpretáción de los tratados con la relación de Hersch Lauterpacht. El relator señaló que "Ia larga experiencia de los tribunales internacionales en materia de interpretación de los tratados parece indicar que nos enfrentamos aquí con un caso en el cual es preferible tener pocas más bien que muchas reglas". Esta experiencia, dijo, "justifica y requiere una declaración por parte de L'Institut de Droit International, acerca de las principales reglas que rigen en esta materia". Inclusive una declaración en forma negativa "contribuiría en amplia medida a la elucidación del aspecto jurídico del problema, disuadiendo de que se recurra a formulae consagradas por el tiempo, pero básicamente inútiles". Valdría la pena, también, "disuadir del uso de formulae huecas". ${ }^{61}$ El relator propuso discutir los siguientes cinco temas centrales de la interpretación de los tratados: los problemas del sentido ordinario o claro, los de los trabajos preparatorios, los de la interpretación restrictiva, los de la interpretación extensiva, y los de la intención de las partes. ${ }^{62}$ Después de una discusión detallada de cada uno de estos temas, el relator llegó a las siguientes conclusiones en su Proyecto de Resoluciones: ${ }^{63}$

El fin principal de la interpretación es la determinación de la intención de las partes. En esta búsqueda, el sentido natural de los términos es el punto de partida. A la parte que alegue que los términos en cuestión tienen un sentido diferente de su sentido natural, toca la carga de probar esto. La claridad aparente o supuesta de esos términos no puede justificar el rechazo de la prueba en contrario, ni tampoco hacerla difícil indebidamente. Los trabajos preparatorios, siempre que sean accesibles, son un medio legítimo y deseable para determinar la intención de las partes dondequiera que el significado de los términos de un tratado sea controvertible. El principio de la interpretación restrictiva sólo juega un papel insignificante en la práctica. Podrá recurrirse a él, para determinar la intención de las partes, en el caso extremo de que todos los demás medios fallen. El principio de la interpretación extensiva, empero, constituye "una guia legítima y un criterio sólido en las materias de la interpretación, siempre y cuando su utilización no haya sido excluida por una clara indicación de las partes en contrario". Aunque la intención de las partes es "un elemento decisivo en la interpretación de los tratados, no siempre es un elemento exclusivo e indispensable. En caso de que falte una intención verdadera de las partes, es deber de los órganos internacionales competentes... llenar las lacunae que resulten de esto y decidir las divergencias de acuerdo con los requisitos fundamentales de la integridad del derecho y de la justicia internacionales". Finalmente, el relator dijo que es impropio adoptar métodos y principios diferentes según sean tratados con fuerza de ley u otras categorías de tratados.

61 Véase L'Institut de Droit International, Annuaire, 43 (1), 1950, 366, 373 .

62 Véase ibid., $373-74$.

63 Véase ibid., 433-34. 
En los comentarios escritos sobre la relación, se encontró generalmente aceptables las propuestas del relator, salvo en el comentario presentado por Sir Eric Beckett, ${ }^{64}$ en que fueron enérgicamente objetadas. En el derecho internacional, como en el interno (dijo Sir Eric), es muy esencial que haya reglas definidas de interpretación. Esto es necesario para que los tribunales puedan dar razones de sus sentencias en materia de interpretación y defenderse a sí mismos de los cargos de llegar a conclusiones sobre bases arbitrarias y subjetivas. Desarrollar un sistema de reglas de interpretación en el derecho internacional es indudablemente difícil, pero no es más difícil que producir un sistema de reglas para la interpretación de preceptos de derecho nacional y de contratos privados. Sir Eric disiente enérgicamente de la opinión del relator acerca de que la meta principal de la interpretación es determinar la intención de las partes. Por lo que se refiere a los preceptos internos, "las declaraciones sobre la comprobación de la intención son... clisés que tienden a oscurecer más bien que iluminar la verdadera tarea del Tribunal... Hay una ilusión total en las referencias a la supuesta intención de la legislatura en la interpretación de una ley, cuando de hecho es casi seguro que el punto suscitado es algo que la legislatura nunca pensó en absoluto. Esto es inclusive más seguro en el caso de la interpretación de los tratados. Como enseña la experiencia, frecuentemente sucede que la discrepancia entre las partes del tratado surge de algo en que las partes del tratado nunca pensaron cuando se concluyó el tratado..."

Al rechazar la admisibilidad de los trabajos preparatorios, Sir Eric dijo que "si hay una admisión demasiado pronta de los travaux préparatoires, probablemente el Estado que se halle en esa posición sea provisto de una tabula in naufragio, ya que generalmente hay algo en los travaux préparatoires que puede apoyar casi cualquier afirmación". Haciendo suya la opinión de que "el texto del tratado, una vez firmado, asume... una especie de vida propia", concluyó diciendo que "atender a los travaux préparatoires para los fines de interpretación surtiría el mismo efecto que sacar una mano muerta desde la tumba, o someter a un hombre adulto a las prescripciones paternas de su infancia".

En otros comentarios a la relación, los puntos siguientes merecen una mención especial. Herbert Kraus ${ }^{65}$ expresaba dudas sobre la posibilidad y utilidad de codificar las reglas de la inierpretación, señalando que en tales tentativas nadie ha tenido éxito, hasta ahora. Acentuó que "ninguna regla de interpretación está colocada jerárquicamente sobre otra". Esto es verdad particularmente de la máxima según la cual la intención de las partes debería comprobarse. Como ninguna regla de interpretación tiene "una autoridad decisiva para determinar el significado del tratado", una apreciación "en for-

64 Véase su carta de febrero 24 de 1950, publicada ibid., $435-444$.

65 Véasc ibid., $445-47$. 
ma justa es precisamente lo que constituye aquí el arte de los juristas que aplican la ley". Una idea similar fue expresada por Gabriele Salvioli, 60 quien dijo que "cuando existen dudas substanciales sobre el resultado interpretativo, o sea, cuando la aplicación de diversos medios de interpretación no termina en el mismo resultado, el árbitro o juez internacional deberá interpretar el tratado... salvaguardando siempre la buena fe, en el sentido en que se ajustaría a los principios de solidaridad internacional y de justicia".

Sir Arnold McNair67 estuvo escéptico acerca del valor de los trabajos preparatorios como criterio determinante de la interpretación de los tratados. Considero que eran sólo "un apoyo, una medida auxiliar, un suplemento -que únicamente debe ser utilizado, en caso de dificultad, con un cuidado escrupuloso". Charles Rousseau ${ }^{68}$ expresó algunas vacilaciones sobre "la adopción de un método unitario de interpretación, independientemente de la naturaleza jurídica del tratado en disputa". Alfred Verdross ${ }^{69}$ consideró necesario hacer algunas adiciones a las propuestas del relator. Así, dijo que todos los acuerdos internacionales deben ser interpretados "a la luz del derecho internacional general", que él consideraba como una de las reglas fundamentales de la interpretación de los tratados. Ligada a esta regla hay otra, "de acuerdo con la cual todo el derecho internacional positivo debe ser interpretado a la luz de los principios generales del derecho reconocidos por las naciones civilizadas".70

Las Observaciones Suplementarias del relator, presentadas a la Conferencia del Institut en Siena en abril de 1952, incluían extractos de algunos comentarios adicionales, especialmente los de Max Huber. ${ }^{71}$ Huber acentuaba que lo esencial de todo acuerdo contractual, incluyendo los tratados, "cs la voluntad concordante de las partes". Sin embargo, "el texto de un contrato tiene una existencia que es independiente de la voluntad de las partes, desde el momento en que estén en desacuerdo acerca de su alcance ( portée)". Ésta es la razón "por Ia cual uno debe ser muy prudente respecto de la admisión de los trabajos preparatorios. El texto firmado, salvo raras excepciones, es la única y más reciente expresión de la voluntad común de las partes". Por lo demás, señaló que tales "reglas simplistas y algo crudas, como la de la interpretación restrictiva..., sólo son aplicables en caso de que el texto se preste a dos interpretaciones 'naturales', 'ordinarias' o 'claras', entre las que el juez podría escoger". Huber opinaba también que había necesidad

66 Véase ibid., 455 .

67 Véase ibid., $45^{\circ}$.

68 Véase ibid., $45 \%$

69 Véase ibid., 455-56.

70 Las otras adiciones sugeridas por él fueron el recurso a los principios que rigen la materia de donde se deduce el texto del tratado y una exposición de los principios que deberian observarse en caso de un tratado se formule en diversas lenguas. véase ibid., $45^{6}$.

7 Véase Annuaire 44 (1), 1952, 199-202. 
de distinguir, para los fines de interpretación, entre tratados que crean derecho y otros tratados.

En las Conclusiones a sus Observaciones Complementarias, el relator consideró necesario hacer ciertas modificaciones a su Proyecto de Resoluciones. ${ }^{72}$ En cuanto a los trabajos preparatorios propuso añadir: "En cualquier caso, los tribunales deben apreciar si es necesario, y hasta qué punto, un examen detallado de los trabajos preparatorios, cuando se da una manifiesta ausencia de toda dificultad que impida hacer valer el sentido ordinario y natural de los términos del tratado." "Las estipulaciones de los tratados deberían interpretarse (o es permisible que lo sean) a la luz de los principios generales del derecho internacional consuetudinario."

En la Conferencia de Siena, los puntos tratados en los comentarios hechos por escrito, fueron reiterados por varios oradores en las discusiones sobre el Proyecto de Resoluciones del relator. ${ }^{73}$ También surgieron algunos puntos adicionales. Jules Basdevant observó que "la interpretación de un tratado es esencialmente una operación del arte juridico, para el cual la ciencia del derecho es ciertamente indispensable, pero no suficiente".74 Frede Castberg consideró que no era posible prescindir de la intención común de las partes en la interpretación de los tratados; pero, dijo, "la cuestión no siempre versa sobre la intención psicológica o fáctica, sino sobre la intención racional, que puede llamarse 'construida' ".75

En la conferencia de Siena, se llegó a un acuerdo unánime sobre el hecho de que "si la conformidad de las partes se realizó sobre el texto del tratado, es propio (il y a lieu) tomar el sentido natural de este texto como base del proceso de la interpretación".70

En vista de las opiniones contradictorias expresadas en las deliberaciones, el relator prefirió que el Institut no decidiera mediante voto el texto de las Resoluciones.77

La fase final de las deliberaciones del Institut tuvo lugar en la Sesión en Granada, en abril de $195^{6.78}$ Sir Hersch Lauterpacht, debido a su trabajo como Juez de la Corte Internacional de Justicia, no pudo acudir a la Conferencia, en la que Sir Gerald Fitzmaurice actuó como relator.

El relator anterior había proporcionado la versión final de su Proyecto de Resoluciones el 19 de octubre de 1953. Esta versión ya no decía enfáticamente que la búsqueda de la intención de las partes era la finalidad principal de la interpretación, pero aún retenía la misma idea de manera modi-

72 Véase ibid. $221,216,217$.

73 En abril 23 y 25 de 1952. Véase Annuaire 44 (2) 1952, 356-406.

74 Véase ibid., 375 .

75 Véase ibid. 377 .

76 Véase ibid. $\mathbf{3} 81$.

77 Véase ibid. 4o6. $^{\circ}$

78 Véase Annuaire 46, 1956, 317-349. 
ficada, aplicando una forma condicional. ${ }^{79} \mathrm{El}$ Proyecto es igualmente menos enfático sobre el punto de los trabajos preparatorios, considerándoles sólo como uno "entre los medios legitimos y deseables para determinar la intención de las partes". ${ }^{80}$ Completamente nuevo en el Proyecto es el artículo 3, que dice que "los principios de la interpretación restrictiva pueden utilizarse únicamente en casos excepcionales, en donde todos los otros medios hayan fallado para determinar la intención de las partes".

De los puntos tratados en las discusiones de la Conferencia de Granada, pueden mencionarse los siguientes. Jules Basdevant, reiterando un punto tratado anteriormente en la Conferencia de Siena, dijo que "la interpretación de un tratado es una obra de arte y las reglas que el Institut puede establecer sobre este tema, sólo pueden tener el carácter de prescripciones directivas, y no imperativas". 81

Esta opinión fue rechazada por Paul Guggenheim, el cual sostenía que "es inexacto decir que la interpretación de los tratados es un arte, lo cual parece excluir la posibilidad de puntualizar los principios de la interpretación. Evidentemente no se trata, en esta materia, de proponer reglas rígidas de interpretación, pero de todos modos uno puede establecer cierta jerarquía entre los principios interpretativos". ${ }^{82}$

Sobre este comentario, Evard Hambro advirtió: desde el punto de vista de que la interpretación de los tratados es un arte, no se sigue que uno no pueda proponer reglas de interpretación. Pues "las reglas existen tanto en los asuntos artísticos como en los jurídicos". ${ }^{83}$

En la Conferencia de Granada se desarrolló una discusión importante sobre el problema de si "el sentido ordinario y natural" de los términos es una fórmula adecuada. Gilbert Gidel sugirió que la palabra "natural" fuese sustituida por "aparente". ${ }^{44}$ Esta modificación no fue aceptada favorablemente y el relator sugirió que el sentido "ordinario y natural", como una expresión consagrada por los tribunales internacionales, debia retenerse. ${ }^{85}$

En la sesión plenaria final de la Conferencia, el relator presentó un Proyecto de Resoluciones completamente nuevo, que se convirtió en la base de las deliberaciones subsecuentes, y fue adoptado, con algunas modificaciones, por 35 votos con 6 abstenciones, sin ningún voto contrario, en la redacción siguiente: 88

79 Véase el Artículo 5 del Proyecto: "Aunque la intención de las partes es un elemento decisivo en la materia de la interpretación de los tratados, no siempre es exclusivo o indispensable."

80 Véase el Artículo 2 del Proyecto.

81 Véase Annuaire $46,1956,3^{22}$.

82 Véase $i$ ibid. 327 .

83 Véase ibid. 328 .

84 Véase ibid. 326 .

85 Véase ibid. 331 .

88 Véase ibid. $34^{8-49}, 35^{8-59}$. 
L'Institut de Droit International considera que, cuando se trate de la interpretación de un tratado, los Estados, las Organizaciones y los Tribunales internacionales podrían inspirarse en los siguientes principios:

\section{Articulo primero}

1) Si la conformidad de las partes se realizó sobre el texto del tratado, es propio tomar el sentido natural y ordinario de los términos de este texto como base de la interpretación. Los términos de las estipulaciones del tratado deben ser interpretados en su contexto entero, de acuerdo con la buena fe y a la luz de los principios del derecho internacional.

2) Sin embargo, si se determina que los términos utilizados deben entenderse en un sentido distinto, el sentido natural y ordinario de estos tẻrminos deberá hacerse a un lado.

\section{Articulo segundo}

1) En caso de que sea llevada una controversia ante un tribunal internacional, éste tiene el deber de considerar, tomando en cuenta las disposiciones del artículo primero, si, y hasta qué grado, es propio utilizar otros medios de interpretación.

2) Entre los medios legítimos de interpretación están:

a) El recurso a los trabajos preparatorios.

b) La práctica observada en la aplicación efectiva de los tratados.

c) El examen de las finalidades del tratado.

Las Resoluciones adoptadas por la Conferencia de Granada no representan la propuesta para una ley de interpretación de los tratados, sino sólo la formulación de ciertas líneas rectoras que "podrían inspirar" (ni siquiera que deberian inspirar) al intérprete. Los principios correspondientes no son presentados en un orden jerárquico definido, ni la lista de los principios pretende ser exhaustiva. Las Resoluciones no se pronuncian claramente por la teoría subjetiva $u$ objetiva de la interpretación, aunque parecen entenderse mejor a la luz de la teoría objetiva. La justicia y la razón como ideas regulativas de la interpretación no son mencionadas en las Resoluciones, ni se dice nada sobre la interpretación restrictiva. La importancia del sentido natural y ordinario de los términos como base para la interpretación ha encontrado en ellas un reconocimiento claro, así como la importancia de la buena fe y los principios del derecho internacional.

Puede parecer que es realmente muy modesto lo que las Resoluciones han alcanzado. Lo que dicen parece tener validez aun sin decirlo. Quizás su 
importancia principal resida en el hecho negativo de oponerse a dar una forma rígida a los principios de la interpretación, ofrecer un "derecho" elaborado $y$, sin embargo, inadecuado para la interpretación de los tratados, y a decidirse en favor de cualquiera de los conceptos básicos de interpretación en pugna. El acuerdo a que se llegó sobre las Resoluciones, muestra que fue alcanzado, como sucede en tantas materias de índole internacional, sólo porque los resultados se dejaron abiertos en formulaciones abstractas, generales y aun no obligatorias. De todos modos, las Resoluciones no parecen haber abierto ningún camino importante en las aporiae de la interpretación de los tratados.

Esto puede ser considerado como decepcionante. Lo que resultó del laborioso trabajo del Institut parece reforzar el escepticismo prevaleciente acerca del valor de los cánones interpretativos, 87 y aun su condenación como totalmente inútiles. ${ }^{88}$ Las Resoluciones del Institut pueden considerarse más decepcionantes aun por el hecho de que no faltaban ni competencia, ni talento, ni buena voluntad, en quienes participaron en su trabajo. A más de eso, ninguna discrepancia ideológica basadaren culturas nacionales o tradiciones jurídicas obtuvo preeminencia alguna en las discusiones. En contraste con los debates de varias organizaciones sobre el problema de definir la agresión, las discusiones sobre el problema hermenéutico por los miembros del Institut tuvieron lugar en un ambiente de plena neutralidad política y dogmática.

Si las Resoluciones adoptadas por el Institut constituyen un fracaso, las siguientes circunstancias deben haber determinado ese fracaso. La tarea que el Institut se había impuesto a sí mismo era abrumadora; las tres Conferencias dedicadas a ella y los estudios dirigidos hacia ahí no bastaron precisamente para dominarla. Así, el problema no fue articulado con propiedad y el saber aplicable a esta materia no fue utilizado adecuadamente. Esto. puede explicar que apenas si se dijo algo durante las deliberaciones que no hubiese sido dicho claramente por los clásicos o por las autoridades judiciales o por los eruditos del derecho. 89 En estos asertos hay una abundancia

87 Vease, por ejemplo, Lord McNair, op. cit. supra, nota 1, pág. 366: "Nosotros esta. mos entre aquellos que son escépticos respecto al valor de esas llamadas reglas y simpati. zamos con el proceso de su gradual devaluación, de la que existen indicaciones." Véase tam. bién Stone, artículo citado supra, nota 6, págs. 352-363.

88 Véase A. Ross, On Law and Justice, 1958, 153-54: "Las máximas de la interpretación varían de un país a otro. Pero muestran dondequiera los mismos rasgos fundamenta. les: son conjuntos asistemáticos de frases capciosas... y tan imprecisas en el significado, que pueden fácilmente manejarse de manera que conduzcan a resultados contradictorios. Como no existen criteria objetivos para mostrar cuándo debiera aplicarse una máxima más bien que otra, ofrecen gran espacio para que el juez llegue al resultado que estime deseable." Cf. J. L. Brierly, The Law of Nations: An Introduction to the International Law of Peace ( $5^{\text {a }}$ ed. 1955) 234, quien pretende que "no existen reglas técnicas en el derecho internacional para la interpretación de los tratados".

89 Véase, por ejemplo, la "Regla de Oro" de la interpretación jurídica expuesta por 
de formulaciones que uno puede escoger o rechazar como expresiones de principios de la interpretación de los tratados, pero no una base suficiente para alcanzar una debida integración de conocimientos y puntos de vista en esa materia. La considerable experiencia de derecho interno que existe en la interpretación jurídica, puede haber sido inaplicable en gran medida al trabajo del Institut, debido a que las situaciones interpretativas del derecho internacional e interno parecen ser diversas en aspectos importantes. También parece haber una diferencia fundamental entre la situación interpretativa perteneciente al derecho internacional tradicional, en relación con el cual fueron desarrolladas varias reglas de interpretación de los tratados, y la situación interpretativa correspondiente al derecho internacional de hoy. Finalmente, el Institut podría haber tenido un concepto erróneo de su tarea cuando trató de proporcionar un conjunto de reglas para todo el derecho de los tratados, en vez de tratar de formular conjuntos especiales de reglas para la interpretación de clases especiales de tratados. El relator Lauterpacht y la mayoría de los miembros del Institut estuvieron demasiado confiados al adherirse al punto de vista de que no había diferencia, para los fines de la interpretación de los tratados, entre los que establecen derecho y otros. Muy probablemente esta diferencia existe y es importante, y además, hubiera sido necesario considerar las diferencias que existen entre la naturaleza jurídica de los tratados de política internacional, por ejemplo, y de los tratados económicos, cartas de organizaciones internacionales y convenciones concernientes a asuntos humanitarios. ${ }^{00}$

Quizás sea equitativo decir que las Resoluciones del Institut alcanzaron todo lo que podía alcanzarse en vista de los múltiples inconvenientes contra los cuales tuvo éste que luchar. Quizás en el nivel de abstracción en que le era posible formular los principios de la interpretación de los tratados, las Resoluciones constituyen inclusive un acierto notable. De ninguna manera

Lord Blackburn en River Wear Commissioners v. Adamson 2 A. C. 742, pág. 746, quien, después de sostener que "el oficio de los jueces no es legislar, sino declarar la intención expresada por la legislatura", prosigue diciendo que "debemos tomar la ley entera juntamente, e interpretarla toda juntamente, dando a las palabras su significación ordinaria, excepto cuando, aplicadas así, produzcan algo incongruente o absurdo o inconveniente, tan grande como para convencer al tribunal de que la intención podría no haber sido usarlos en su significación ordinaria, y para justificar que el tribunal les atribuyera alguna otra significación, que, aunque menos propia, es la que el tribunal piensa que las palabras ostentan". Véase también Blackstone, Commentaries 1 (8ª ed. 1778) 59-62.

80 Cf. Hogg, artículo I, citado supra, nota 26 , p. 441, quien señala que los casos decididos por el Tribunal Internacional de Justicia "pueden sugerir que el tribunal adopta un punto de vista basado en su discrecional poder, cuando está involucrada la Carta de las Naciones Unidas o alguna otra actividad de uno de sus órganos; otro punto de vista sería el que se adopta cuando el texto es un tratado comercial". Cf. y también "A Symposium on Statutory Construction", Vanderbilt Law Review 3, 1950, 365-643, en que se hace el intento de aislar los problemas pertenecientes a tipos especiales de legislación. Para una expresión de la apreciación de este enfoque, véase el "Foreword" de Mr. Justice Felix Frankfurter al Symposium, ibid., 365, pág. 368 . 
reprimen la elaboración de códigos especiales de interpretación en sectores particulares del derecho de los tratados, ni desacreditan las colecciones existentes de máximas correspondientes. Muchos principios que están contenidos, por ejemplo, en el arsenal de De Vattel, pueden aún mostrarse útiles como guías adicionales para "inspirar" a los intérpretes de tratados en circunstancias apropiadas. Lo que surgió de las deliberaciones del Institut puede en un respecto ser considerado definitivamente como de un valor positivo considerable: varios pensamientos que salieron en la disçusión acentuaron puntos importantes acerca de la naturaleza de la interpretación jurídica en general y el status intelectual de sus normas especificas. Haremos referencia a estos pensamientos en nuestra siguiente tentativa de colocar el presente problema en un contexto intelectual adecuado.

\section{Los Principios de la Interpretación de los Tratados como Tópoi Juridicos}

Si las reglas de la interpretación jurídica son reglas de derecho o no, puede considerarse como una cuestión meramente académica, pero sigue siendo una cuestión que requiere respuestas a fin de que podamos tener apoyos propios en las aporiae de la interpretación de los tratados. En el nivel teórico, la respuesta a esta cuestión depende de cómo se defina el concepto del derecho: parece ser factible definir el derecho de tal manera que incluya las reglas de la interpretación jurídica, y también de tal manera que las excluya. En el nivel práctico, la respuesta a esta cuestión es que los órdenes jurídicos reales son libres de incorporar reglas específicas o inclusive sistemas de reglas como elementos suyos, sea para la totalidad del orden jurídico o para sectores específicos de él. Estos sistemas de reglas de interpretación pueden ser, inclusive, "normativamente cerrados", en el sentido de que hay un principio remanente negativo de interpretación, y que dice, por ejemplo, que todo lo que no puede decidirse mediante reglas explícitas de interpretación, deberá ser considerado como algo que impone al sujeto del deber la obligación menos gravosa entre todas las posibles. $O$, para formularlo concisamente, la regla de in dubio mitius podría fungir como tal principio. Sin embargo, los órdenes jurídicos también son libres para abstenerse de todo sistema de reglas de interpretación "orientadas axiomáticamente" y para incorporar sólo un sistema de tales reglas que se oriente según tópoi. Este parece ser el caso de la mayoría de los órdenes jurídicos y seguramente el del orden jurídico internacional. Sólo el derecho penal en los órdenes jurídicos locales ofrece un ejemplo evidente de lo que se acerca a un sistema de reglas de interpretación orientado axiomáticamente.

Sea que podamos, o no, considerar como un sistema el cuerpo de reglas de interpretación que son parte de un orden jurídico, o que sin ser parte suya obran sobre él desde afuera, el tópos como categoría de pensamiento es 
lo que parece pertenecer a la mayoría de ellos. Que la mayoría de las reglas de la interpretación jurídica deben ser concebidas como tópoi jurídicos resulta de la circunstancia de que son "anulables", recusables, ${ }^{91}$ discordantes en ciertos respectos y en ciertos contextos, ${ }^{92}$ y requieren evaluación y elección final por parte del intérprete, una elección que es una elección razonable. ${ }^{83}$ Así, las reglas de la interpretación juridica apenas pueden ser principios para una demostratio juridica: más bien son principios para una inventio jurídica, ${ }^{94}$ o sea, son principios para el descubrimiento de significados jurídicamente apropiados. Su aplicación es guiada por pautas tales como la buena fe, razonabilidad y prudencia, que por sí mismas constituyen no axiomata, sino tópoi. Así, es propio considerarlos como "lugares" de la argumentación, dentro de los cuales el intérprete puede buscar y encontrar lo que es necesario para la aplicación del derecho en el caso dado, ${ }^{95}$ y no como premisas de las cuales se pueden sacar conclusiones respecto del interpretantum, mediante operaciones meramente lógicas. Por lo tanto, es perfectamente factible considerar la interpretación jurídica como una ciencia y como un arte al mismo tiempo,96 un punto bien tratado por Jules Basdevant y Edvard

91 Cf. Betti, op. cit. supra, nota 8, pág. 254 , quien caracteriza el proceso de la interpretación como un "processo di discussione e di escussione (Auseinandersetzug)" Cf. también Silving, artículo citado supra, nota ${ }_{15}$, pág. 522, el cual dice que "las reglas de interpretación, en cuanto recibidas e incorporadas a los códigos, se conservan en la Europa continental en la misma forma en que fueron pensadas por los juristas romanos, como una colección asistemática de sabiduria. En los paises del common law, sin embargo, el hecho de que una regla esté en contradicción con otra no es un impedimento necesario para su carácter legal. El sistema entero del common law es un sistema para elegir, entre reglas opuestas, aquella que es la más apropiada para la situación de un hecho dado". Cf. además el American Law Institute, Restatement of the Foreign Relations Law of the United States: Proposed Official Draft, 1962, 539, 544-45, que describe las "reglas" de interpretación como uno de los factores que la experiencia internacional mostró ser guías (o apoyos) útiles.

92 Sobre discrepancias de las reglas de interpretación juridica véase $\mathbf{K}$. N. Llewellyn, "Remarks of the Theory of Appellate Decision and the Rules or Canon about how Statutes Are to be Construed", Vanderbilt Law Review 3, 1950, 395, págs. 401-06.

93 Cf. de Visscher, op. cit. supra, nota 9, págs. 51-52, quien dice que "le travail de l'interprète sur un texte est celui d'une pensée en mouvement. Cet aspect dynamique de l'interpretation est trop souvent perdu de vue." Caracterizan las operaciones mentales que el abogado ejecuta en la interpretación, como "infinement souples et diverses par lesquelles l'esprit s'achemine a la recherche d'une conviction". (Ibid. 52).

94 Cf. ibid. 13: “...l'interprétation judiciaire releve de l'esprit de finesse plus que de l'esprit de géométrie."

95 Cf. ibid. 70: "les regles d'interpretation fournissent au juge des hypotheses de travail; il ne les retient $q u$ ' à titre purement provisoire et toujours sous reserve d'une vérification ulterieure." "En somme, la principale utilité des fameux 'canons' d'interprétation est de rendre l'interprète attentif aux options qui s'offrent a son choix." Cf. también Recaséns Siches, op. cit. supra, nota 20, pág. 119; K. Larenz, Methodenlehre der Rechtswissenschaft, $1960,236$.

96 Que no hay nada erróneo en considerar la interpretación legal, a la vez como ciencia y como arte, fue expresado ya por Savigny, System des heutigen römischen Rechts 1 , 1840, 206 y sigs., 211. Cf. Larenz, op'. cit., 236. Cf. también Betti, op. cit. supra, nota 8, pág. 252, el cual concibe la interpretación a la vez como "una elaboración evaluadora" y como un trabajo de "inteligencia dialéctica". 
Hambro en el curso de las deliberaciones del Institut. ${ }^{97}$ No hay duda de que la razón, especialmente en su uso práctico, es capaz de un arte penetrante así como de una ciencia. El arte también tiene sus reglas, y.éstas pueden ser científicamente elaboradas y concebidas como principios ordenados dentro de alguna especie de sistema.

Como se ha dicho que la actividad científica está involucrada en la interpretación jurídica, la relación de la lógica, como un instrumento importante del pensamiento científico, con la interpretación, requiere un examen especial. La aplicación de la lógica presupone la interpretación. Antes de poder razonar lógicamente, tenemos que colocar los términos y las frases del lenguaje ordinario en una forma lógica propia; esto requiere la interpretạción de la materia prima lingüística que manejamos. Pero en cada paso particular de nuestra argumentación, en cuanto hayamos logrado asentimiento para una formulación lógicamente utilizable, debemos obedecer las reglas de la lógica, si queremos sacar conclusiones de ella. Que nuestra meta intelectual sea la inventio o una prueba rigurosa, la lógica (en el sentido de la lógica formal y no en el sentido de la lógica "material", "logique passionnelle", y semejantes) es indispensable como un instrumento del pensar. Para una prueba rigurosa, la lógica es todo lo que se necesita, siempre y cuando estén dadas las premisas para su aplicación; para la inventio se necesita mucho más, pero aquélla sigue siendo indispensable como parte del instrumental para el "descubrimiento". Así, existe una complementariedad e interpretación de las actividades lógicas y "retóricas" de la mente en la interpretación jurídica. Sería un lamentable concepto erróneo de la interpretación o de la lógica, o de ambas, el pensar que la lógica es en cierto sentido ajena a la interpretación. Los elementos alógicos de la interpretación son sólo un cierto aspecto de la interpretación, elementos que pueden merecer un énfasis, pero no un énfasis exagerado. La aplicación apropiada de la lógica en la interpretación es uno de los factores más importantes que hacen de la interpretación jurídica un pensamiento disciplinado, un dominio de la razón práctica, una actividad "científica", y algo más que mero arte.

Aparte de los principios de consistencia lógica, la interpretación jurídica está también, y eminentemente, regida por principios de consistencia práctica. Estos últimos requieren estabilidad de actitudes, atención comprensiva de los intereses básicos más bien que de los superficiales y transitorios, proporcionamiento a otros de expectativas razonables, y acción por referencia a normas capaces de universalización. ${ }^{98}$ La razón práctica se ocupa de actitudes y acciones humanas, dirigiéndolas no sólo de acuerdo con ciertos principis, sino también hacia ciertos principios. Es una incumbencia de la razón

o7 Véase suṕra notas 72, 84 .

98 Véase J. Ladd "Reason and Practice" en J. Wild (ed.), The Return to Reason, 1953, 295. pág. 257. 
práctica evitar que las decisiones de donde resultan estas actitudes y acciones surjan del caos, mantengan caos y creen caos. Su principal empeño es hacer uso del orden, conservarlo y aumentarlo en los asuntos humanos. La interpretación jurídica, para ser razonable en el sentido de la razón práctica, debe regirse por principios en un triple sentido: debería aprovecharse de los principios existentes, debería evitar deslizarse hacia una actividad no regida por principios y debería refinar y, de ser factible, crear principios de acuerdo con los cuales la interpretación jurídica pueda ser dirigida con mayor razonabilidad en el porvenir.

En este punto podemos tratar algunos problemas específicos que han jugado un papel mayor en las perplejidades sobre la interpretación jurídica, incluyendo la interpretación de los tratados. En primer lugar: ¿qué es lo interpretantum, propiamente concebido? Los nombres que comúnmente utilizamos para él son: la "intención" o la "voluntad" del legislador, por una parte, y el "significado objetivo" de los preceptos jurídicos, por otra. En cuanto a las primeras, puede consinderarse ahora como una base común que estas palabras no deben entenderse en su sentido psicológico. Que pueden ser utilizadas aun en un sentido especial, técnico, fue señalado en la Conferencia del Institut en Siena, por Frede Castberg, quien caracterizó la "intención" de que se trata aquí, como una "intención racional, que puede llamarse "construida". ${ }^{30}$ En el contexto de la discusión jurídico-filosófica del problema de la interpretación jurídica, la misma idea encontró una formulación elocuente en Gustav Radbruch, que adopta el punto de vista de que lo interpretantum es "el significado objetivamente válido de una regla jurídica". La llamada intención del legislador debe considerarse interpretativamente como su intención. "Por tanto es posible determinar como voluntad legislativa algo que nunca existió en las voluntades conscientes de los autores de la ley... La ley puede ser más sabia que sus creadores $-\mathrm{y}$, en efecto, debe ser más sabia que sus creadores." Hábilmente Radbruch caracteriza la interpretación jurídica como una "mezcla de elementos teóricos y prácticos, perceptivos y creadores, reproductivos y productivos, cientificos y transcientíficos, objetivos y subjetivos. En la medida, empero, en la que la interpretación es práctica, creadora, productiva, transcientífica, es determinada en cada caso por las variables necesidades del derecho". ${ }^{100}$ Radbruch elabora la misma idea comparando la interpretación filológica y la jurídica: mientras que la primera

99 Véase supra, p. 3. Cf. Frankfurter, artículo citado supra, nota 92, pág. 367, quien cita a Oliver Wendell Holmes, el cual dice que la intención es "una cláusula residual que intenta recoger cualesquiera otros auxilios que pueda haber para la interpretación junto a las palabras particulares y al diccionario". El autor no proporciona ninguna cita, excepto que esto procede de una carta de Holmes.

100 Véase G. Radbruch, Rechtsphilosophie ( $5^{\text {a }}$ ed. 1956), 211. Cf. Myres S. McDougal, "International Law, Power, and Policy: A Contemporary Conception", Recueil des Cours 82, 1953, 137, pág. 152 . 
es "repensamiento de una idea ya pensada", la segunda es pensar hasta el fin lo que una vez fue pensado (zu Ende Denken des Gedachten)". Concibe la ciencia del derecho como ciencia práctica, que "debe comprender una norma jurídica mejor que las personas que participaron en su creación", y debe "derivar de aquélla más de lo que esas personas pusieron ahi".,101

Junto a la elucidación del significado de lo interpretantum, estos pensamientos de Radbruch muestran también otro punto importante acerca de la interpretación jurídica: que es determinada por la situación jurídica general del momento en que tiene lugar la interpretación. Esto apoya el punto de vista de Alfred Verdross, adoptado en las Resoluciones del Institut, de acuerdo con el cual la interpretación de los tratados debe efectuarse considerando los principios del derecho internacional, que son, desde luego, los principios válidos en el momento de la interpretación. ${ }^{102} \mathrm{Si}$ la situación general del derecho internacional ha cambiado, la situación interpretativa de sus estipulaciones ha sido afectada y también la interpretación de los tratados debe tomar el curso correspondiente. ${ }^{103}$

También puede considerarse como una base común que la interpretación jurídica, como un dominio de la razón práctica, contiene innegablemente algo que trasciende la objetividad y el rigor científicos: contiene un elemento subjetivo, evaluador, apreciativo, un elemento decisivo introducido por el intérprete, y que aún debe ser controlado por la razón. A través de este elemento, el enlace interpretativo que existe entre el autor del texto interpretado y el intérprete propende a aflojarse. ${ }^{104}$ Las reglas de interpretación exactamente formuladas y su promulgación como parte del orden jurídico dado, pueden servir como medios para reducir el poder discrecional del

101 Véase Radbruch, op. cit., $210,214 \mathrm{e}$ id. Vorschule der Rechtsphilosophie, 1947, 9. Cf. Llewellyn, artículo citado supra, nota 96 , pág. 400: "Pero el lenguaje es requerido para expresar circunstancias totalmente incontempladas al tiempo de su paso. Aquí no es propiamente la indagación del sentido buscado ordinalmente para ser puesto dentro, sino más bien del sentido que puede extraerse de ahí a la luz de la nueva situación." Cf. también Larenz, op. cit., supra, nota 99, pág. 253, quien dice que "la 'totalidad de propositos' no se da de antemano al intérprete, sino sólo como una tarea para él". Savigny dio una atractiva expresión a la misma idea, diciendo que a fin de que la regla jurídica pueda convertirse en parte de la vida, "es necesario que hagamos algo por nuestra parte, esto es, que la incorporemos a nosotros de una cierta manera". "Lo que se requiere de nuestra parte, es una actividad intelectual." Véase Savigny, op. cit., nota 1oo, pág. 207. Cf. Harvard Research citado supra, nota 1, pág. 946; McDougal, articulo citado supra, nota 104, pág. 153 .

102 Cf. J. A. Bishop, Bishop on Criminal Law (9: ed. por J. M. Zane y otros, 1929) par. 29ı b: "Una ley es simplemente una partícula fresca de materia legal vertida en un océano de derecho previamente existente."

103 Cf. F. S. Cohen, "Field Theory and Judicial Logic", Yale Law Journal 59, 1950, 238, pág. $25^{\circ}$, quien señala que cuando en la valoración del órgano jurisdiccional hay un cambio fundamental en una área del derecho, puede afectar la interpretación del derecho en otras áreas.

104 Véase Frankfurter, artículo citado supra, nota 92, pág. $3^{66}$. 
intérprete. ${ }^{10 a}$ Sin embargo, éste puede ejercitar sólo un control relativo sobre el juicio del intérprete $-\mathrm{y}$ sólo en algunos campos bien definidos del derecho. Pues la vaguedad parece ser un concomitante inerradicable de la expresión jurídica. ${ }^{106}$ Los abogados no han encontrado una panacea para eliminar la vaguedad en el derecho; los remedios ofrecidos por los filósofos parecen tener sólo una eficacia relativa, en lo que concierne a la práctica jurídica. ${ }^{107}$ El mejor remedio que la experiencia jurídica ha proporcionado al respeto es el establecimiento, por prescripción legal, de instituciones que tienen la última autoridad para determinar lo que un término vago o un concepto mal definido debe significar en un caso particular. La necesidad de estas instituciones es sugerida por la naturaleza misma de la razón práctica, que sólo puede funcionar a través de agentes humanos capaces de comprensión, de juicio 108 y de opinión. Por lo tanto, puede decirse que la función judicial de los órdenes jurídicos es de una importancia primordial ${ }^{100} \mathrm{Y}$ éste es el motivo por el cual la debilidad de esta función en el orden jurídico internacional es una de las principales fragilidades del derecho internacional, que no puede remediarse con un simple incremento de su volumen o con tentativas de proporcionar unas definiciones juridicamente obligatorias que funcionen oprimiendo un botón.

El dilema básico con que se enfrenta cualquier intérprete del derecho es el de asegurar certidumbre jurídica mediante una interpretación predecible del derecho y, al mismo tiempo, hacer concesiones a los cambios jurí-

105 Cf. Hogg, artículo citado suppra, nota 26 , pág. 40o, quien señala que la comprension de la gente sobre lo que se le dice requiere "un fondo común entre el que habla y el que escucha, una asociación común entre el pensamiento y las palabras usadas. La estrechez de la relación entre pensamiento, palabra y comprensión dependerá de la naturaleza de la materia que postula la habilidad del que habla para dar expresión exacta a sus pensamientos".

106 Cf. Ch. P. Curtis, "A Better Theory of Legal Interpretation" Vanderbilt Law Review 3, 1950, 407, pág. 424 .

107 Véase, por ejemplo, M. Black, Problems of Analysis: Philosophical Essays, 1954, 14, 42, quien introduce la idea de una "definición de alcance"; que pretende ocuparse de nociones que no pueden definirse de una manera precisa. La definición de alcance contiene una descripción de los principales factores involucrados, una determinación de su peso e importancia relativas, y un cálculo de su modo de interacción. Los casos de determinación de alcance no están unificados por ninguna caracteristica común. Están relacionados unos con otros como un "spectrum de ejemplos... mediante criteria gradualmente variados". Existen, por supuesto, casos ejemplares claros en que la aplicación es obvia.

108 Al final de su tratamiento de la interpretación de los tratados, De Vattel dice que todas las reglas de interpretación que ha formulado, "deberían combinarse juntamente, y la interpretación del derecho o tratado debería hacerse en concordancia con ellas en el grado en que son aplicables en el caso dado. Cuando parecen chocar, se contrabalancean mutuamente y se limitan una a otra de acuerdo con su fuerza e importancia, y según que se apliquen más particularmente al caso concreto". Véase De Vattel, op. cit. supra, nota 1o, libro II cap. xvii, par. 322. Esta advertencia procede obviamente del supuesto de que existen agentes humanos apropiados para desplegar la razón práctica.

109 Véase Recaséns Siches, op. cit. supra, nota 2o, págs. 273-74. 
dicos, sin los cuales el derecho no puede vivir y que no pueden introducirse únicamente a través de los canales legislativos, sino que requieren también la participación del intérprete del derecho. ${ }^{110}$ Este dilema es particularmente molesto en el campo del derecho internacional, ya que el juez internacional está bajo una presión particularmente fuerte para no hacer, sino sólo aplicar el derecho. Así, debe conservar a todo precio la apariencia de no añadir o quitar nada al derecho para cuya aplicación fue llamado. Esta apariencia es muy difícil de mantener, en caso de indeterminación, falta de claridad, y vaguedad de los términos de un tratado, frente a las reclamaciones opuestas de las partes que pretenden que esos términos aún tienen "objetivamente" el significado que conviene a su causa. Como cualquier intérprete del derecho, cuando el juez internacional se enfrenta a la tarea de interpretar un tratado, tiene disponibles tres enfoques principales para esta tarea: el enfoque analítico, el enfoque de política social y el enfoque de la intuición libre. Sobre estos enfoques, Wolfgang Friedmann ha observado que "el enfoque analítico proporciona guías útiles para el caso rutinario, pero falla totalmente en la solución de nuevas situaciones o problemas marginales, que son cuantitativamente limitados pero cualitativamente muy importantes. El enfoque de política social ofrece una orientación razonablemente clara sólo para la interpretación de aquellos decretos que tienen un objetivo social claro y definido. El enfoque de la intuición libre abre el camino a la incertidumbre, al prejuicio y a premisas mayores inarticuladas". 111 En cuanto al enfoque de política social, por más prometedor que sea en el terreno del derecho interno, es casi tan precario en el terreno del internacional como el enfoque de la intuición libre. En este campo no tenemos hombres cuya intuición exija respeto universal. $Y$ tampoco tenemos, en casos importantes, programas bien delimitados de política social universalmente compartidos.

Como estos tres enfoques de la interpretación juridica parecen cubrir el campo entero, debemos contentarnos con procurar trabajar con ellos lo mejor que podamos. Sobre todo, debemos tratar de comprender más claramente lo que se implica en el hecho de ser abandonados en la incertidumbre y duda por los principios que rigen la interpretación jurídica. Cuando hablamos de seguridad jurídica y acentuamos su importancia, es necesario, como ha señalado Luis Recaséns Siches, preguntar: ¿Seguridad en qué sentido? Es verdad que: "El deseo de ccrteza y seguridad es uno de los móviles fundamentales en la vida humana... Sin embargo, el deseo de seguridad no actúa como factor exclusivo ni siquiera predominante en la vida humana, sino que persiste simultáneamente y a la misma altura con deseos contrarios, tales como el afán de cambio, la aspiración de mejora, e incluso el atractivo

110 Cf. R. Pound, Introduction to the Philosophy of Law (ed. revisada, 1954) 9, 13 111 Véase W. Friedmann, "Statute Law and Its Interpretation in the Modern State" Canadian Bar Review 26, 1948, 1277, pág. 1 soo. 
de la aventura." La seguridad del derecho sería una meta que vale la pena sólo si "lo jurídico es un medio especial para dar certeza y para asegurar la realización de aquellos fines que una determinada sociedad considera como de cumplimiento necesario". Recaséns Siches concluye que la certeza y seguridad en la injusticia, en el mal, en la insolidaridad, en la servidumbre, vendrían a hacer esas calamidades más dolorosas de lo que serían si se presentasen solamente como irrupciones casuales. ${ }^{112}$

Esto nos lleva a concluir que es esencial en el terreno del derecho internacional, como en otros campos, equilibrar el esfuerzo hacia la seguridad jurídica con el esfuerzo hacia otros valores de igual rango. Esta conclusión pone cargas extremamente pesadas sobre los hombros de los guardianes del derecho internacional. Implica que, además de encontrar su camino entre los embrollos de las conexiones del pensamiento jurídico en su campo y entre la confusión y abstrusidad de los problemas lógicos y semánticos, deben estar bien orientados, igualmente, en los problemas de los valores éticos y políticos pertinentes al derecho. Grandes incertidumbres y divergencias de opiniones prevalecen especialmente en este terreno en el pensamiento jurídico internacional. Las preguntas: ¿Qué es la justicia?, ¿Qué es el bien común?, ¿Qué es el interés público? y ¿Cuáles son exactamente sus criterios?, nos enfrentan a aporiae también en el campo del derecho internacional, pero carecen de respuestas satisfactorias. Respuestas tentativas plausibles y respuestas que podrían establecerse como aproximaciones utilizables a las soluciones de estos problemas, son ahogadas en el clamor de las batallas ideológicas de los políticos y en la disputa académica entre las mentes eruditas.

Todo esto refuerza nuestra sentencia de que la interpretación de los tratados es esencialmente un asunto de razonamiento retórico. Opera esencialmente en terrenos de la razón práctica a los que sólo podemos entrar por Holzwege..$^{113}$ Es regido sobre todo por tópoi y requiere limitaciones y una disciplina de pensar característica de este razonamiento, sobre todo la disciplina resultante de la integridad del que razona. ${ }^{114}$ De este razona-

112 Véase Recaséns Siches, op. cit. supra, nota 20, págs. 272, 278, 286. Cf. G. Allport, Pattern and Growth in Personality, 1961, 558: "El hombre... no es una creatura homostática. No busca equilibrium dentro de sí mismo y con el ambiente. Su inquietud es sistémica, y demasiado profundamente arraigada para adormecerla con satisfacciones temporales. Busca una fórmula más sólida para,vivir, algo que le permita superar la enajenación y el sufrimiento." Cf. también ibid. 560: "El hombre es intrínsecamente inquieto y ansioso, y desea a la vez seguridad y libertad."

113 Sobre esta metáfora véase M. Heidegger, Holzwege, 1957, g, quien expresa la. idea de las sendas que conducen a lo inaccesible de un bosque espeso, conocidas y holladas sólo por los leñadores.

114 Cf. Hogg, artículo 1, supra, nota 26, pág. 369 , quien dice que los acontecimientos del periodo después de la segunda Guerra Mundial "o seguramente de este siglo, han proporcionado no sólo poca evidencia de alguien que confia en alguien, sino igualmente poca razón de por qué lo hacen". Estos hechos ponen en foco preciso el problema de la integridad de los pensadores jurídicos internacionales. 
miento puede surgir una mayor articulación de las reglas de la interpretación, una mejor definición de sus relaciones mutuas, y otras mejoras para fines prácticos limitados o inclusive en el nivel teórico del problema. Pero, como resultado de la naturaleza de la interpretación jurídica, todo esto aún significaría sólo un ordenamiento relativo de los "lugares" del argumento en cuestión; previsiblemente no significaria que el derecho internacional u otro cuerpo de normas que contenga los principios de la interpretación de los tratados "funcionara puramente", en el sentido de la pureza de sistemas regidos sólo por los principios de la razón teórica. Si el intérprete de los tratados quiere contribuir eficazmente a este proceso, probablemente no baste que se haga un perito en tecnicismos puramente juridicos. Como la interpretación juridica es una actividad que ocupa a todas las facultades humanas relativas al razonamiento disciplinado y circunspecto, debe aquél aspirar, no sólo a ser un verus philosophus, capaz de obtener conocimientos de la "naturaleza de las cosas", 115 encontrados en la interpretación, sino también a crear lás condiciones que le permitan desplegar en su actividad l'esprit de finesse al lado de l'esprit de géometrie.

Ilmar TAMMELO

Universidad de Sydney (Australia)

(Traducción de Guillermo Floris Margadant).

115 La frase: "la naturaleza de las cosas", ha logrado aceptación reciententente también en el Tribunal Internacional de Justicia. Véase Case Concerning the Temple of Preah Vihear (Merits), (1962), I. C. J., Repiorts (1962), 101, discrepando el Juez Sir Percy Spender; la Opinión Consultiva sobre Certain Expenses of the United Nations (Article r7. Paragraph 2, of the Charter), 1962, I. C. J., Reports, 1962, 155. En cuanto a la historia y los problemas de esta frase y noción, véase I. Tammelo, "The Nature of Facts as a Juristic Tópos", Archiv für Rechts- und Sozialphilosophie, Cuaderno Adicional 39, 1969, 297-260. 